\title{
Pengaruh Total Abdominal Histerektomi (Tah) Terhadap Dyspareunia Dan Seksualitas Pada Pasangan Suami Istri
}

\author{
Barkah Wulandari \\ STIKES Notokusumo Yogyakarta \\ Barkah.wulandari@gmail.com
}

\begin{abstract}
ABSTRAK
Total Abdominal Histerektomi (TAH) merupakan ancaman bagi seorang wanita karena hilangnya fungsi reproduksi dan fungsi seksual akibat pengangkatan uterus dan serviks (Briedite et al, 2014). Hal ini dihubungkan dengan fungsi rahim yang berperan dalam kontraksi selama fase orgasm dan pengangkatan serviks menyebabkan anatomi vagina menjadi pendek yang mempengaruhi gejala dyspareunia (nyeri selama koitus dan berhubungan seksual) dan sensasi yang berubah selama koitus (Jacquia et al, 2014). Penelitian ini untuk mengungkapkan temuan mengenai pengaruh TAH atas indikasi benign terhadap dyspareunia dan seksualitas pasangan suami istri. Penelitian ini merupakan penelitian non eksperimental dengan pendekatan cross secsional. Jumlah sampel dalam penelitian ini adalah 31 orang wanita post TAH. Terdapat hubungan positif dyspareunia dengan kepuasan seksual $p=0,009(p<0,05)$. Koefisien korelasi positif, semakin tinggi skor dyspareunia maka semakin tinggi kepuasan seksual dengan keeratan kategori sedang 0,462 (0,400-0,599). Usia, lama TAH, usia pernikahan, jumlah anak, pendidikan dan pekerjaan tidak ada hubungannya dengan kejadian dyspareunia dan kepuasan seksual. Tingkatan dyspareunia yang dirasakan oleh responden setelah TAH sebagian besar berada pada kategori dyspareunia ringan (64,5\%). Tingkatan dyspareunia ringan terjadi di kedua kelompok yaitu subjek yang ada perbaikan seksual $(66,7 \%)$ maupun subjek merasakan ada penurunan seksual $(57,1 \%)$. Tidak ada hubungan antara dyspareunia dengan kejadian TAH ( $P>0.05)$. Hanya saja terdapat hubungan antara dyspareunia dengan kepuasan seksual.
\end{abstract}

Kata Kunci : Dyspareunia, Kepuasan seksual, Total Abdominal histerektomi

\section{ABSTRACT}

Total Abdominal Hysterectomy (TAH) is a threat to a woman due to loss of reproductive function and sexual function due to removal of the uterus and cervix (Briedite et al, 2014). This is related to the function of the uterus that plays a role in contractions during the orgasm phase and cervical removal causing short vaginal anatomy which affects symptoms of dyspareunia (pain during coitus and sexual intercourse) and altered sensations during coitus (Jacquia et al, 2014). This research is to reveal findings regarding the effect of TAH on benign indications on dyspareunia and sexuality of married couples. This research is a nonexperimental research with a cross-sectional approach. The number of samples in this study were 31 post-TAH women. There was a positive relationship between dyspareunia and sexual satisfaction $p=0.009(p<0.05)$. The correlation coefficient is positive, the higher the dyspareunia score, the higher sexual satisfaction with moderate category closeness is 0.462 (0.400-0.599). Age, duration of marriage, age of marriage, number of children, education and work have nothing to do with dyspareunia and sexual satisfaction. The level of dyspareunia felt by respondents after TAH was mostly in the mild dyspareunia category (64.5\%). The level of mild dyspareunia occurred in both groups namely the subjects who had sexual improvement (66.7\%) and the subjects felt a sexual decline (57.1\%). There was no relationship between dyspareunia and the incidence of TAH ( $P>0.05)$. It's just that there is a relationship between dyspareunia with sexual satisfaction.

Keywords: Dyspareunia, Sexual satisfaction, Total Abdominal Hysterectomy

http://ejournal.urindo.ac.id/index.php/kesehatan

Article History :

Sumbitted 27 Mei 2020, Accepted 29 Juni 2020, Published 30 Juni 2020 


\section{PENDAHULUAN}

Total abdominal histerektomi (TAH) merupakan salah satu metode pembedahan dengan mengangkat servik dan rahim. Bagi seorang wanita, histerektomi merupakan ancaman karena hilangnya fungsi reproduksi dan juga fungsi seksual, hal ini dihubungkan dengan fungsi rahim yang berperan dalam kontraksi selama fase orgasm (Böös J \& Shoultz, 1992). Pengangkatan serviks menyebabkan anatomi vagina menjadi pendek yang mempengaruhi gejala dyspareunia (nyeri selama koitus dan berhubungan seksual) dan sensasi yang berubah selama koitus (Sheth dan Studd, 2003). Hal ini juga sesuai dengan penelitian Demirtas \& Pinar (2013) yang menyebutkan bahwa histerektomi radikal menyebabkan penurunan pelumasan vagina yang dapat menyebabkan dyspareunia.

Selain itu pengangkatan ovarium melalui prosedur oophorektomi juga menyebabkan wanita kehilangan hormon seks, sehingga terjadi peningkatan keluhan mengenai hasrat seksual pada wanita setelah TAH (Böös J \& Shoultz, 1992). Disisi lain fungsi ovarium yang merupakan organ penghasil estrogen yang berpengaruh terhadap lumbrikasi vagina, jika terjadi penurunan maka menyebabkan kekeringan vagina/ dyspareunia (Wallach dan Eisenberg, 2003).

$$
\text { Berdasarkan penelitian yang }
$$

dilakukan oleh Greimel et al (2009) menyebutkan bahwa wanita yang telah menjalani tindakan TAH atas indikasi kanker serviks mengatakan keluhan yang biasa dirasakan adalah dyspareunia yang menyebabkan mengeluhkan berkurangnya kenikmatan seksual dengan pasangan. Penelitian yang dilakukan oleh Clarke, et al. (1995) menyebutkan bahwa terdapat gangguan dalam aktivitas seksual. Hal yang sama dikemukakan oleh Penelitian Ussher, et al. (2012) yang mengatakan bahwa 53\% responden memiliki nilai FSFI dibawah 26,55 (fungsi seksual terganggu).

Penelitian terkait seksualitas dan histerektomi sudah pernah dilakukan, namun masih terpisah dalam kaitannya kedua variabel tersebut. Penulis tertarik untuk melakukan penelitian secara lebih mendalam mengenai pengaruh Total Abdominal Histerektomi (TAH) terhadap dyspareunia dan seksualitas pada pasangan suami istri

\section{METODE}

Penelitian ini merupakan penelitian non eksperimental dengan pendekatan kuantitatif rancangan cross secsional digunakan untuk mengungkapkan temuan mengenai pengaruh TAH atas indikasi benign terhadap dyspareunia dan seksualitas pasangan suami istri.

Penelitian ini dilakukan di masingmasing rumah responden dimana memiliki riwayat pernah menjalani tindakan TAH atas indikasi benign atau non malignan di 
RSUD Panembahan Senopati Bantul, memiliki riwayat minimal 3 bulan dan maksimal 2 tahun setelah TAH, Sexual active, memiliki contact person (Nomor handphone atau nomor telepon) di data rekam medis dan masih aktif, bertempat tinggal di wilayah Yogyakarta.

Alasan pengambilan sampel penelitian di RSUD Panembahan Senopati Bantul karena merupakan salah satu rumah sakit daerah dimana sebagian besar pasien berasal dari area Yogyakarta. Sedangkan alasan pengambilan sampel pada responden yang bertempat tinggal di area Yogyakarta karena berdasarkan data Riskesdas (2013) Yogyakarta menempati prevalensi tertinggi untuk angka kejadian tumor dan kanker di Indonesia. Penelitian ini dilakukan selama 4 bulan. Jumlah sampel sebanyak 31 orang dengan metode pengambilan sampel consecutive sampling.

Instrumen yang digunakan dalam penelitian kuantitatif adalah ceklist berupa kuesioner yang berisi data pribadi dan sosial demografi dan kuesioner yang berisi kuesioner Female Sexual Function Index (FSFI): Dyspareunia dan Sexual Satisfaction Scale for Women (SSS-W). Kuesioner FSFI digunakan untuk mengukur fungsi seksual 4 minggu terakhir.

\section{HASIL PENELITIAN}

Karakteristik subyek penelitian merupakan wanita dengan riwayat TAH atas indikasi benign dimana memiliki rerata usia 45 tahun dan dengan rentang usia 2758 tahun. Rerata lama TAH pada wanita dalam penelitian ini adalah 17,94 bulan, dengan rentang 4-24 bulan. Sebagian besar wanita dalam penelitian ini bekerja $(74,2 \%)$ dan $25,8 \%$ tidak bekerja dengan profesi yang dapat memberikan penghasilan, yaitu ibu rumah tangga. Sedangkan rerata usia pernikahan wanita dalam penelitian ini adalah 19,90 tahun, dengan rentang usia pernikahan 2-30 tahun. Rerata jumlah anak yang dimiliki 1,84, dengan rentang jumlah anak 0-4 anak.

Sedangkan pendidikan wanita dalam penelitian ini sebagian besar menempuh pendidikan lanjutan $(41,9 \%)$ dan perguruan tinggi $(41,9 \%)$, selebihnya menempuh pendidikan dasar. Jika dilihat dari perubahan yang dirasakan responden setelah TAH, sebanyak $77,4 \%$ merasa membaik/ ada perbaikan seksualitas dan sebanyak 7\% merasa menurun setelah TAH. Data mengenai karakteristik wanita setelah Total Abdominal Histerektomi (TAH) dapat dilihat pada tabel 1. 
Tabel 1.

Karakteristik Wanita setelah Total Abdominal Histerektomi (TAH)

$(n=31)$

\begin{tabular}{lrcc}
\hline \multicolumn{1}{c}{ Karakteristik } & Mean \pm SD & Frekuensi & Persentase \\
\hline Usia (tahun) & $45,71 \pm 7,58$ & & \\
Lama TAH (bulan) & $17,94 \pm 6,93$ & & \\
Usia pernikahan (tahun) & $19,90 \pm 6,86$ & & \\
Jumlah anak & $1,84 \pm, 97$ & & \\
Pekerjaan & & & \\
$\quad$ Bekerja & & 23 & $74,2 \%$ \\
$\quad$ Tidak bekerja & 8 & $25,8 \%$ \\
Pendidikan & & & \\
$\quad$ SD & & 5 & $16,1 \%$ \\
$\quad$ SMP & & 0 & $0,0 \%$ \\
$\quad$ SMA & 13 & $41,9 \%$ \\
$\quad$ PT & & 13 & $41,9 \%$ \\
Perubahan setelah TAH & & \\
$\quad$ Merasa membaik & & 24 & $77,4 \%$ \\
$\quad$ Merasa menurun & & 7 & $22,6 \%$ \\
\hline
\end{tabular}

Tingkatan dyspareunia yang wanita menunjukkan bahwa wanita tidak dirasakan oleh responden setelah TAH nyeri ketika melakukan hubungan seksual. sebagian besar berada pada kategori Terdapat 16,1\% wanita yang mengeluhkan dyspareunia ringan (64,5\%). Dyspareunia dyspareunia berat (skor dyspareunia 0-2.4. dikategorikan ringan jika memiliki skor 4,0- Penggolongan dyspareunia dan persentase 6,0, sedangkan pada skor dyspareunia 6,00 dapat dilihat pada tabel 2 .

Tabel 2

Persentase kategori dyspareunia Pada wanita setelah Total Abdominal Histerektomi (TAH)

$(n=31)$

\begin{tabular}{clcc}
\hline Karakteristik & \multicolumn{1}{c}{ Kategori } & N & \% \\
\hline Dyspareunia & Ringan & 20 & $64,5 \%$ \\
& Sedang & 6 & $19,4 \%$ \\
& Berat & 5 & $16,1 \%$ \\
\hline
\end{tabular}

Tabel 3

Perbedaan perubahan seksualitas

Pada wanita setelah Total Abdominal Histerektomi (TAH)

$(n=31)$

\begin{tabular}{lrrrrrrrr}
\hline & \multicolumn{7}{c}{ kat_dyspareunia } \\
\cline { 2 - 9 } PERUBAHAN & \multicolumn{2}{c}{ Berat } & \multicolumn{2}{c}{ Sedang } & \multicolumn{2}{c}{ Ringan } & $\mathrm{p}$ \\
\cline { 2 - 9 } SETELAH TAH & $\mathrm{n}$ & $\%$ & $\mathrm{~N}$ & $\%$ & $\mathrm{~N}$ & $\%$ & \\
\hline Merasa membaik & 4 & $16,7 \%$ & 4 & $16,7 \%$ & 16 & $66,7 \%$ & 0,738 \\
Merasa menurun & 1 & $14,3 \%$ & 2 & $28,6 \%$ & 4 & $57,1 \%$ & \\
\hline
\end{tabular}


Hasil uji statistik dengan Mann Whitney menunjukkan bahwa sebagian besar subjek mengalami dyspareunia ringan. Tingkatan dyspareunia ringan terjadi di kedua kelompok yaitu subjek yang ada perbaikan seksual $(66,7 \%)$ maupun subjek merasakan ada penurunan seksual (57,1\%). Hanya saja walaupun ada persamaan dalam kejadian dyspareunia dikedua kelompok, namun $p$-value $>0,005$ Sehingga tidak menunjukkan perbedaan bermakna.

Tabel 4

Perbedaan rata-rata Dypareunia dan Kepuasan Seksual Pada wanita setelah Total Abdominal Histerektomi (TAH)

$\mathbf{n = 3 1 )}$

\begin{tabular}{|c|c|c|c|c|c|}
\hline & \multicolumn{4}{|c|}{ PERUBAHAN SETELAH TAH } & \multirow{4}{*}{$p$} \\
\hline & \multicolumn{2}{|c|}{ Merasa membaik } & \multicolumn{2}{|c|}{ Merasa menurun } & \\
\hline & & Standard & & Standard & \\
\hline & Mean & Deviation & Mean & Deviation & \\
\hline Dyspareunia & 4,16 & 2,00 & 3,83 & 1,44 & 0,389 \\
\hline Kepuasan seksual & 117,54 & 17,67 & 108,57 & 15,05 & 0,130 \\
\hline
\end{tabular}

Hasil uji statistik dengan Mann

Whitney, menunjukkan rata-rata dyspareunia pada subjek yang membaik 4,16 lebih tinggi dibandingkan yang merasa menurun 3,83. Begitu juga dengan kepuasan seksual, berdasarkan tabel diatas kepuasan seksual lebih tinggi pada subjek yang membaik 117,54 dibandingkan subjek yang merasa menurun 108,57. Namun tidak ada perbedaan bermakna dyspareunia dan kepuasan seksual antara subjek yang membaik atau menurun $(p>0,05)$.

Tabel 5

Hubungan Variabel Luar Dengan Dyspareunia dan Kepuasan Seksual $(n=31)$

\begin{tabular}{lcccccc}
\hline & \multicolumn{2}{c}{ Dyspareunia } & \multicolumn{2}{c}{$\begin{array}{c}\text { Kategori } \\
\text { dyspareunia }\end{array}$} & \multicolumn{2}{c}{ Kepuasan seksual } \\
\cline { 2 - 7 } & $\mathrm{r}$ & $\mathrm{P}$ & $\mathrm{R}$ & $\mathrm{p}$ & $\mathrm{R}$ & $\mathrm{p}$ \\
\hline Usia (tahun) & $-0,111$ & 0,551 & $-0,109$ & 0,559 & 0,203 & 0,274 \\
Lama TAH (bulan) & $-0,049$ & 0,793 & 0,014 & 0,942 & $-0,099$ & 0,595 \\
Usia pernikahan (thn) & $-0,144$ & 0,438 & $-0,09$ & 0,631 & 0,162 & 0,384 \\
jumlah anak & 0,048 & 0,799 & $-0,071$ & 0,704 & 0,057 & 0,761 \\
Pendidikan & 0,258 & 0,161 & 0,173 & 0,353 & 0,155 & 0,406 \\
Pekerjaan & $-0,329$ & 0,071 & $-0,331$ & 0,069 & $-0,172$ & 0,354 \\
\hline
\end{tabular}

Hasil statististik dengan korelasi spearman menunjukkan semua variabel dalam karakteristik responden memiliki $p$ value $>0,05$. Hal ini menjelaskan bahwa tidak ada hubungan variabel luar dengan dyspareunia maupun kepuasan seksual. 


\section{Jurnal Bidang Ilmu Kesehatan}

Usia, lama TAH, usia pernikahan, jumlah anak, pendidikan dan pekerjaan tidak ada hubungannya dengan kejadian dyspareunia dan kepuasan seksual. Ada faktor-faktor lain yang berhubungan dengan dyspareunia atau kepuasan seksual diluar variabel dalam karakteristik responden.

Tabel 6

Hubungan antara Dyspareunia dan Kepuasan Seksual Pada wanita setelah Total Abdominal Histerektomi (TAH)

( $n=31)$

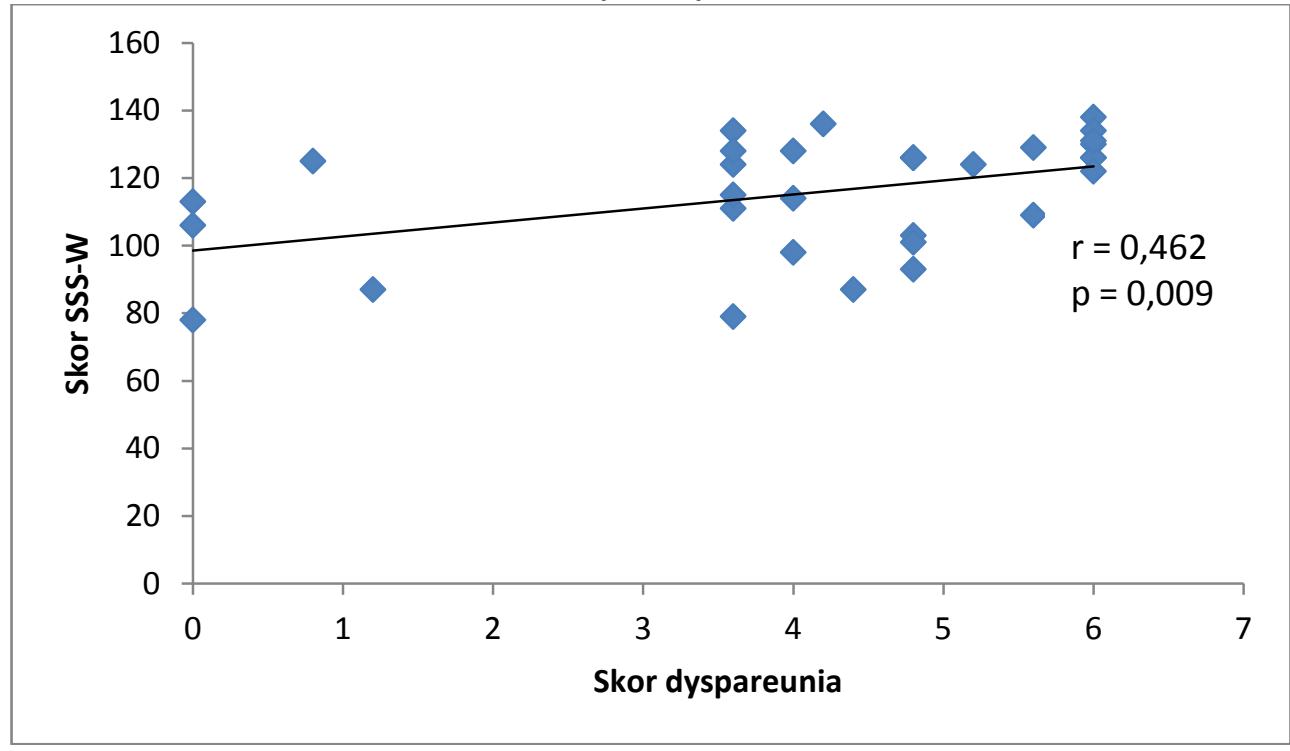

Berdasarkan tabel 5 diatas, terdapat hubungan positif dyspareunia dengan kepuasan seksual $p=0,009$ $(p<0,05)$. Koefisien korelasi positif, semakin tinggi skor dyspareunia maka semakin tinggi kepuasan seksual dengan keeratan kategori sedang $0,462 \quad(0,400-0,599)$. Semakin tinggi skor dyspareunia maka semakin rendah keluhan pasien akan dyspareunia. Sehingga berdasarkan tabel diatas, semakin rendah keluhan dyspareunia maka semakin tinggi kepuasan seksual.

\section{PEMBAHASAN}

Dyspareunia adalah rasa nyeri saat koitus yang terjadi karena beberapa penyebab, sepeti adanya iritasi klitoris, endometriosis, insufisiensi lumbrikasi vagina, jaringan parut pada vagina, infeksi, vaginitis (Hamilton, 1995). Dalam penelitian ini, pengangkatan serviks tidak ada hubungannya dengan nyeri dan ketidaknyamanan selama melakukan aktivitas seksual. Fungsi seksual berkorelasi dengan kepuasan seksual, penelitian ini menunjukkan bahwa domain dyspareunia berkorelasi dengan kepuasan seksual.

Ada beberapa faktor yang didapatkan dari hasil penelitian ini, yaitu responden mengatakan ada perbaikan seksualitas setelah TAH karena tidak mengeluhkan dyspareunia, kembalinya 
aktivitas seksual dan dukungan suami. Hal ini sesuai dengan penelitian Sharp et al (2000) yang melaporkan bahwa dyspareunia tidak terjadi setelah histerektomi atas indikasi benign, tindakan penutupan vaginal cuff tidak memberikan efek dyspareunia. Disamping itu tidak ada bukti mengenai kurangnya suplai darah lokal maupun gangguan syaraf akibat perubahan anatomi setelah TAH. Penelitian tersebut menambahkan bahwa seksualitas dipengaruhi faktor psikologis, sosial dan fisiologis (Mokate, et al., 2006).

Pengangkatan rahim juga tidak menyebabkan vagina memendek, bila dokter melakukan teknik menggantung tunggul/puncak rahim. Dimana vagina ditarik dan dilekatkan dengan ligament (Schorge, et al., 2008). Banyak penelitian menunjukkan bahwa kepuasan seksual mengalami perbaikan setelah histerektomi, terutama pada pasien yang sebelumnya dengan indikasi menorraghagia atau nyeri panggul. Setelah TAH mengalami proses perbaikan karena tindakan bedah mengatasi keluhan sebelum TAH dan wanita lebih mudah untuk menerima hubungan seksual kembali (Fortner, et al., 2007).

Hal ini juga didukung oleh Schiff et al (2015) menyebutkan bahwa tidak ada perbedaan signifikan antara Total Abdominal Histerektomi dengan supraservikal histerektomi jika dikaitkan dengan aktivitas seksual setelah 6 bulan tindakan operasi karena indikasi benign. Nyeri yang dialami selama 3 bulan dalam penelitian tersebut tidak berasal dari dyspareunia tetapi dari lokasi lain yaitu daerah sekitar panggul. Tidak ada perbedaan signifikan mengenai kepuasan seksual antara kelompok TAH dan histerektomi supraservikal. Dalam penelitian ini menunjukkan tindakan baik TAH dan histerektomi supraservikal tidak menimbulkan dyspareunia pada pasien sehingga mempengaruhi tingkat kepuasan seksual dengan pasangan. Nyeri sedikit dirasakan setelah operasi. Hal tersebut sesuai dengan penelitian ini bahwa nyeri ringan yang terjadi pada responden tidak berkaitan dengan efek TAH.

Schiff et al (2015) juga menyebutkan bahwa tidak ada perbedaan signifikan antara Total Abdominal Histerektomi dengan supraservikal histerektomi jika dikaitkan dengan aktivitas seksual setelah 6 bulan tindakan operasi karena indikasi benign. Nyeri yang dialami selama 3 bulan dalam penelitian tersebut tidak berasal dari dyspareunia tetapi dari lokasi lain yaitu daerah sekitar panggul. Tidak ada perbedaan signifikan mengenai kepuasan seksual antara kelompok TAH dan histerektomi supraservikal. TAH dan histerektomi supraservikal tidak menimbulkan dyspareunia pada pasien sehingga mempengaruhi tingkat kepuasan seksual dengan pasangan. Hal ini sesuai dengan penelitian ini yang menunjukkan 
bahwa dyspareunia berkorelasi dengan kepuasan seksual.

Penurunan hasrat seksual dan frekuensi hubungan seksual pada beberapa minggu setelah TAH dan BSO, namun tidak ada perbedaan yang signifikan dalam kepuasan hubungan seksual dan dyspareunia yang dirasakan oleh pasien antara sebelum sakit dan setelah TAH (Kuscu et al, 2005). Hal ini sesuai dengan penelitian ini, dimana pemulihan pasca operasi memberikan dampak positif dalam aktivitas seksual.

Dilain sisi, Doğan et al (2018) menyebutkan bahwa dyspareunia dan vaginismus tidak mengganggu pernikahan. Hal ini dikarenakan ada beberapa hal yang mempengaruhi kepuasan seksual pasangan suami istri, antara lain: karakteristik individu yang meliputi sosio demografi dan keadaan psikologis wanita, fungsi dan respon seksual, dukungan sosial dan keluarga serta keyakinan agama. Dukungan keluarga meliputi komunikasi dengan pasangan, hubungan yang baik dengan anak-anak dan keluarga, status sosial ekonomi keluarga (Fuentes et al, 2014). Heiman et al (2011) juga menyebutkan bahwa lama pernikahan juga mempengaruhi kepuasan seksual, hubungan yang lebih panjang diprediksi menentukan kebahagiaan didalam pernikahan tersebut). Akan tetapi dalam penelitian ini tidak sesuai dengan Fuentes et al (2014) dan Heiman et al (2011), karena berdasarkan uji statistik tidak ada hubungannya kejadian dyspareunia dan kepuasan seksual dengan usia, lama pernikahan, pendidikan, pekerjaan.

Histerektomi karena indikasi benign meningkatkan kualitas hidup pasien, peningkatan harga diri pasien setelah TAH mempengaruhi peningkatan seksual. Hal ini sesuai dengan penelitian Eken et al (2016), dengan tidak adanya dyspareunia, ketidaknyamanan hubungan seksual maupun risiko kanker rahim setelah TAH menjadikan ke

\section{SIMPULAN}

1. Tidak ada hubungan antara dyspareunia dan kepuasan seksual pasangan suami istri dengan kejadian TAH $(P>0.05)$.

2. Terdapat hubungan antara dyspareunia dengan kepuasan seksual.

3. Adanya peningkatan kepuasan seksual diperoleh karena tidak mengeluhkan nyeri ketika melakukan hubungan seksual setelah TAH, kembalinya aktivitas seksual dan dukungan suami.

\section{DAFTAR PUSTAKA}

Briedite I, Ancane G, Rogovska I, Lietuviete N. Quality of Female Sexual Function After Conventional Abdominal Hysterectomy-Three Month'Observation. Acta Chirurgica Latviensis. 2014; 14(1): 26-31 
Böös J, Nathors \& Shoultz B, Von. 1992. Psychological reactions and sexual life after hysterectomy with or without oophorectomy. Gynecol Obstet Invest; 34(2):97-101.

Clarke, Aileen et al. 2005. Indications for and outcome of total abdominal hysterectomy for benign disease: a prospective cohort study. BJOG An International journal of Obstetrics and Gynarcology. 102: 611-620.

Demirtas B, Pinar G. Determination of Sexual Problems of Turkish Patients Receiving Gynecologic Cancer Treatment: a Crosssectional Study. Asian Pacific journal of cancer prevention: APJCP. 2013; 15(16): 6657-6663

Doğan, S., Saraçoğlu, G. V., Erbek, E., \& Budak, K. (2018). The assessment of penetration cognitions and sexual functionality of women with sexual pain disorder in a Turkish sample: a comparative study. Anadolu Psikiyatri Dergisi, 19(3), 227-234.

Eken, M. K., İlhan, G., Temizkan, O., Çelik, E. E., Herkiloğlu, D., \& Karateke, A. (2016). The impact of abdominal and laparoscopic hysterectomies on women's sexuality and psychological condition. Turkish journal of obstetrics and gynecology, 13(4), 196.

Fortner, K.B., Szymanski, L.M., Fox, H.E., Wallach, E.E. 2007. The Johns Hopkins Manual of Gynecology and Obstetrics Third Edition. New York: Lippincott Williams \& Wilkins.

Greimel, E. R., Winter, R., Kapp, K. S. \& Haas, J. 2009. Quality of life and sexual functioning after cervical cancer treatment: a long term follow up study. psycho-oncology. 18: 476482.

Heiman, J. R., Long, J. S., Smith, S. N., Fisher, W. A., Sand, M. S., \& Rosen, R. C. (2011). Sexual satisfaction and relationship happiness in midlife and older couples in five countries. Archives of sexual behavior, 40(4), 741-753

Jacquia F, Myers EM, Geller EJ. Vaginal versus robotic hysterectomy and concomitant pelvic support surgery: a comparison of postoperative vaginal length and sexual function. Journal of minimally invasive gynecology. 2014; 21(6): 1010-1014

Kemenkes, R. I. (2013). Riset kesehatan dasar (Riskesdas) 2013. Kemenkes RI. Jakarta.Hamilton, P. M. 1995. Dasardasar keperawatan maternitas Edisi 6. Jakarta: EGC. 
Kuscu, N. K., Oruc, S., Ceylan, E., Eskicioglu, F., Goker, A., \& Caglar, H. (2005). Sexual life following total abdominal hysterectomy. Archives of gynecology and obstetrics, 271(3), 218-221.

Mokate, T., Wright, C., \& Mander, T. (2006). Hysterectomy and sexual function. British Menopause Society Journal, 12(4), 153-157.

Sánchez-Fuentes, M. D. M., Santos-Iglesias, P., \& Sierra, J. C. (2014). A systematic review of sexual satisfaction. International Journal of Clinical and Health Psychology, 14(1).

Schiff, L., Wegienka, G., Sangha, R., \& Eisenstein, D. (2015). Is cervix removal associated with patientcentered outcomes of pain, dyspareunia, well-being and satisfaction after laparoscopic hysterectomy?. Archives of gynecology and obstetrics, 291(2), 371-376.

Schorge, J.O., Schaffer, J.I., Halvorson, L.M. Hoffman, B.L, Bradshaw, K.D; Cunningham, F.G., Bradshaw. 2008. Williams Gynecology . New York: The McGraw-Hill.
Sharp HT, Dodson MK, Langer KM, Doucette RC, Norton PA (2000) The role of vaginal apex excision in the management of persistent posthysterectomy dyspareunia. Am J Obstet Gynecol 183:13851389 Sharp HT, Dodson MK, Langer KM, Doucette RC, Norton PA (2000) The role of vaginal apex excision in the management of persistent posthysterectomy dyspareunia. Am J Obstet Gynecol 183:1385-1389

Sheth, Shirish \& Studd, John. 2002. Vaginal Hysterectomy. London: Isis Medical Media.

Ussher, J. M., E.Gilbelt, J. P., Y.Hawkins \& W.K.T.Wong 2012. Sexuality and Intimacy in the Context of Cancer. In Tech.

Wallach, E. E. \& Eisenberg, E. 2003. Hysterectomy: Exploring your options, United States, The Johns Hopkins University Press: 155-169. 